\title{
Las sinergias, un reto para RTVE
}

\author{
Ignacio Marimón Andrés \\ Periodista RNE
}

\section{Introducción}

Grandes compañías buscan desde hace años la sinergia entre sus unidades empresariales. Buscan formas alternativas para que los equipos de trabajo colaboren de una manera más efectiva. El objetivo último es ser más eficiente y, por lo tanto, reducir costes. La integración de los servicios o la eliminación de malas prácticas de trabajo forman parte de esta nueva tendencia que ahora también se está incorporando a los medios de comunicación.

Pero el camino para lograr las sinergias no es fácil. Muchas veces se llevan a cabo en detrimento de la calidad de la información, otras se intentan implantar sin éxito, algunas no pasan de ser modelos conceptuales y, en otras ocasiones, el exceso de positivismo hace que solo nos centremos en los beneficios de las mismas sin contar con los efectos secundarios que generan sobre nuestra empresa.

A veces estas iniciativas distraen la atención de los ejecutivos y priorizan aspectos que no son los que generan beneficios reales a nuestra empresa. Por ello hay que trabajar con cautela en todo este nuevo proceso de integración sobre todo cuando hablamos de empresas de comunicación y especialmente cuando se pretende, como es el caso, unir radio y televisión. Para evitar fracasos habrá que pautar los procedimientos a seguir y mostrar con realismo los pros y los contras de esta nueva estrategia empresarial.

En medio de esta nueva tendencia está RTVE. La Radio Televisión pública afronta en los próximos años un reto importante: convertirse en la primera empresa de comunicación española que intente integrar plenamente sus esfuerzos radio- 
fónicos y televisivos. Mejorar la colaboración entre radio y televisión y que sus profesionales trabajen indistintamente para un medio o el otro, es un objetivo ambicioso que está plagado de escollos.

\section{Los peligros de las sinergias}

Según La Real Academia de la Lengua Española, sinergia es «acción de dos o más causas cuyo efecto es superior a la suma de los efectos individuales».

Y eso mismo es lo que se está intentando aplicar en RTVE, al menos en su estructura territorial. El objetivo final es que todos los profesionales de la comunicación de los centros territoriales, ya sean técnicos o periodistas desempeñen funciones de ambos medios indistintamente. Así un técnico de sonido de radio, deberá aprender el manejo de una cámara o el funcionamiento del control de un plató de televisión. El periodista de radio también deberá aprender el lenguaje y los ritmos televisivos. Y, lo que es más complicado, deberá compatibilizar ambas funciones. Eso significa que será vital para lograr un éxito en este proceso, el sentido común de los directivos que impulsen esta iniciativa. Si se pretende que un informador duplique su esfuerzo para conseguir que realice el mismo trabajo que antes hacían dos personas, el proyecto estará abocado al fracaso. Por poner un ejemplo, una sinergia irreal sería pretender que un periodista grabe y edite sus audios, realice la crónica radiofónica, entre en directo en una conexión en Radio 5 y al mismo tiempo, coja los códigos de tiempo de la cámara de televisión, redacte la noticia y elabore la pieza para su posterior emisión en el telediario.

Para los que trabajamos en esto, parece casi imposible realizar bien todas esas funciones sin que eso suponga un deterioro considerable de la calidad de la información en alguna de sus facetas. Ni los tempos, ni el lenguaje, ni el funcionamiento son los mismos para un medio y para otro. Ello significa que o se planifica y se concretan claramente los campos a integrar, o este ambicioso proyecto no resultará. En ese sentido se antoja necesario realizar cursos de formación a todos los trabajadores para que conozcan los nuevos campos a desempeñar. Unos cursos que serán más vitales para los puestos técnicos pero que también serán necesarios para los creativos.

Por otro lado, resulta imprescindible crear un mecanismo que regule la manera de realizar las sinergias para no dejar nada a la improvisación. Para ello sería interesante que RTVE creará una comisión encargada de pautar estos comportamientos y no que cada centro territorial aplique las sinergias según le convenga.

Me parece interesante destacar la enorme diferencia de ritmos de trabajo que existe entre la radio y la televisión. La radio funciona de una manera mucho más inmediata y directa: sus tempos son muchos más rápidos, aquí y ahora. Su lenguaje es, por defecto, descriptivo ya que no cuenta con la imagen para apoyar 
su discurso. Su estilo se basa en frases cortas, directas y claras evitando en lo posible las subordinadas. Sus únicos aliados, los sonidos, los efectos, los cortes de voz, la música y también el silencio. En televisión se goza de más recursos, las pautas de trabajo son más pausadas. El ritmo de trabajo es más lento, la pieza televisiva requiere mayor elaboración. Su lenguaje también es distinto, no necesita describir, pues esta función ya la desempeña la imagen. La locución precisamente va acompañando a la imagen con un lenguaje conciso, claro y breve. Por ello a la hora de elaborar un mensaje audiovisual, hay que evitar el abuso de adjetivos, que no hacen más que mermar el valor informativo que nos brinda la imagen. En ese sentido, el texto debe complementarse con los otros niveles audiovisuales.

Otro factor a tener en cuenta es que ninguna empresa española de comunicación ha llevado a buen término una sinergia completa entre radio y televisión. La integración absoluta de sus profesionales es un reto complicado, por eso resulta interesante poner límites a las sinergias y buscar un punto intermedio sostenible, eficaz y que mejore el funcionamiento de la empresa.

En este sentido, las sinergias en cuanto al personal directivo y administrativo son mucho más asumibles. Agrupar en un solo puesto, al jefe de personal de TVE y RNE parece algo lógico y fácil de llevar a cabo. Lo mismo ocurre con la agrupación de las direcciones territoriales y de otro tipo de mandos orgánicos duplicados en ambos medios e innecesarios en ocasiones. En este sentido, alcanzar mayor eficacia y eficiencia resulta una meta necesaria en estos tiempos en los que los recortes presupuestarios para RTVE hacen peligrar su sostenibilidad.

Pero la cosa se complica cuando hablamos de los periodistas y técnicos. Ellos deberán aprender una nueva vertiente del oficio, conocer los entresijos de un medio casi desconocido, adaptarse a las nuevas tecnologías y perder la especialización. Saber de todo, en todos los ámbitos, es un objetivo peligroso ya que al final pueden salir a relucir mermas en varios ámbitos. La frase sabemos de todo y no sabemos de nada se extrapolaría aquí a su máxima acepción y conlleva el riesgo de caer en la inoperancia y la mala praxis del sector.

\section{Las sinergias, un camino de doble sentido}

Las sinergias en RTVE tienen otro peligro añadido, caer en el error de que los esfuerzos siempre se deben hacer desde la radio hacia la televisión, supeditando la labor de los profesionales de radio al medio televisivo. Eso es un error que hay que evitar. Las sinergias están confeccionadas para beneficiar a las dos partes implicadas y el feedback en el proceso debe ser total para alcanzar el éxito. No hay un medio más importante que el otro, sino dos servicios públicos esenciales para el ciudadano que deben coordinarse para lograr mejores resultados. 
Por poner un ejemplo, si un redactor radiofónico tiene que hacer mal su crónica, sin el tiempo suficiente para desempeñar bien su trabajo, a costa de realizar una noticia para televisión, eso significara que las sinergias no están cumpliendo su cometido.

Como profesional y amante de la radio, defiendo este medio sobre cualquier otro, la capacidad evocativa e imaginativa que se tiene sobre el oyente supera cualquier expectativa que tenga sobre la televisión. Por eso habrá que defender en este proceso el mantenimiento de la calidad radiofónica que es la que más peligra. Y esto no significa que debamos realizar un enfrentamiento absurdo entre radio y televisión, sobre cuál es más importante. Ambos medios deben complementarse, cada uno mantiene su hueco social desde hace años sin que existía una competencia directa entre ellos. La televisión no es una amenaza para la radio y viceversa, solo hay que saber enfocar las sinergias de manera correcta.

\section{Otras sinergias no menos importantes}

Otra de las sinergias necesarias de un medio de comunicación como RTVE son las relativas al medio e Internet. Tanto la página web como la aplicación para tabletas de la corporación se han convertido en un referente el sector audiovisual español. Este camino hay que reforzarlo. Las sinergias con las redes sociales son necesarias y habría que potenciarlas con un equipo de community managers que se encargaran de gestionar este ámbito. En este sentido, es necesario utilizar las redes para divulgar los contenidos y buscar estrategias para lograr mayores audiencias. El fenómeno de los podcast está suponiendo toda una revolución. La función de RTVE a la carta permite al oyente/espectador acceder a todos los contenidos de los diversos canales de RTVE en cualquier momento y lugar. Además, permite realizar comentarios y valoraciones favoreciendo la interactividad con la audiencia. Ello desvela, entre otras cosas, qué es lo que más interesa a la audiencia, siendo un instrumento muy útil de cara a configurar los contenidos de la programación.

\section{Conclusión}

Nos enfrentamos a un reto durante los próximos años. El objetivo es lograr una empresa sostenible pero no a cualquier precio. Algunos profesionales consideran que en estos tiempos de crisis, privatizaciones, despidos masivos y EREs en medios de comunicación públicos, este proceso de sinergias es el caldo de cultivo idóneo para aquéllos que quieren recortar este servicio esencial para el ciudadano. Las sinergias, en ningún caso, deben suponer una excusa para reducir la plantilla en un futuro no muy lejano. Sin duda eso sería el principio del fin.

Otro de los retos a los que nos enfrentamos es la implicación de todos los agentes en este proceso. Los profesionales de la corporación RTVE debemos de 
luchar porque las sinergias no mermen la calidad de nuestros programas, informativos o conexiones. Somos una marca labrada en el tiempo con una historia que salvaguardar. El devenir social, político y cultural de nuestro país ha sido registrado por nuestros micrófonos, por nuestras cámaras desde hace 75 años. Cientos de maestros de la profesión pasaron antes por aquí. A ellos, y sobre todo a los oyentes/espectadores, se lo debemos.

\section{Referencia de este artículo}

Marimón Andrés, Ignacio (2013). Las sinergias, un reto para RTVE. En: adComunica. Revista Científica de Estrategias, Tendencias e Innovación en Comunicación, $\mathrm{n}^{\circ}$ 5. Castellón: Asociación para el Desarrollo de la Comunicación adComunica, Universidad Complutense de Madrid y Universitat Jaume I, 259-263. DOI: http://dx.doi.org/10.6035/2174-0992.2013.5.18. 